\title{
Optimization of pre-sowing magnetic field doses through RSM in pea
}

\author{
M. Iqbal ${ }^{1}$, I. Ahmad ${ }^{2}$, S.M. Hussain ${ }^{3}$, R.A. Khera ${ }^{1}$, T.H. Bokhari ${ }^{4}$, and M.A. Shehzad ${ }^{5}$ \\ ${ }^{1}$ Department of Chemistry and Biochemistry, ${ }^{5}$ Department of Agronomy; University of Agriculture Faisalabad-38040, Pakistan \\ ${ }^{2}$ Department of Mathematical Sciences, Göteborg University, SE-41296, Göteborg, Sweden \\ ${ }^{3}$ Department of Wildlife and Fisheries, ${ }^{4}$ Department of Chemistry; Government College University, Faisalabad-38000, Pakistan
}

Received February 9, 2012; accepted March 28, 2012

\begin{abstract}
A b s t r a c t. Seed pre-sowing magnetic field treatment was reported to induce biochemical and physiological changes. In the present study, response surface methodology was used for deduction of optimal magnetic field doses. Improved growth and yield responses in the pea cultivar were achieved using a rotatable central composite design and multivariate data analysis. The growth parameters such as root and shoot fresh masses and lengths as well as yield were enhanced at a certain magnetic field level. The chlorophyll contents were also enhanced significantly $v s$. the control. The low magnetic field strength for longer duration of exposure/high strength for shorter exposure were found to be optimal points for maximum responses in root fresh mass, chlorophyll ' $a$ ' contents, and green pod yield/plant, respectively and a similar trend was observed for other measured parameters. The results indicate that the magnetic field pre-sowing seed treatment can be used practically to enhance the growth and yield in pea cultivar and response surface methodology was found an efficient experimental tool for optimization of the treatment level to obtain maximum response of interest.
\end{abstract}

K e y w o r d s: pea, magnetic field, multivariable analysis, photosynthesis, response surface methodology

\section{INTRODUCTION}

Pea (Pisum sativum L. cv. Samrina Zard) is one of the well-known vegetables grown in Pakistan and the richest source of protein ie 6-70 \% in green peas and 18-35\% in dry seeds. It is a good source of vitamins A, B, and C and has a high proportion of minerals. In Pakistan, an estimated average cultivated area of this crop is 135600 ha with an average yield of $6.7 \mathrm{t} \mathrm{ha}^{-1}$ (Amjad and Anjum, 2002; Iqbal et al., 2012; Nisar et al., 2008). Agricultural scientists are trying to enhance the agricultural productivity and the main strategies include expansion of agricultural land, increasing the crop-

*Corresponding author e-mail: bosalvee@yahoo.com ped land, and use of pre-sowing and post-emergence treatments. Land as a whole is a limited resource due to fast population growth. Similarly, increasing the cropped area is not an easy task because of the economic condition of the farmers. Under such conditions, an increase in productivity per unit area is the only option to meet the requirement, which again demands eco-friendly agricultural practices (Amjad and Anjum, 2002).

The effect of magnetic field (MF) treatment on biological systems is well known and a number of studies has been conducted in order to enhance the germination rate, seedling vigour as well as growth at lateral stages of development, and ultimately the yield and other yield components (Iqbal et al., 2012; Marks and Szecówka, 2010). Magnetic field changes the internal moieties of seeds such as free radicals and the concentration of ions and electrical charges and; thus, free movement of ions activates the metabolic pathways by enhancing the biochemical and physiological feedback (Pietruszewski, 2007). Various researchers have studied and reported the effect of magnetic field on different crops and plants such as radish, cotton, rice, oak, lettuce, maize, wheat, sunflower, barley, corn, beans, tomato, and fruit seeds, and consequently, high performance in terms of plant growth, height, yield, seed mass per spike as well as shoot and root length and total fresh and dry masses etc. (De Souza et al., 2006; Fischer et al., 2004; Florez et al., 2007; Martinez et al., 2009). Furthermore, the MF strength and exposure duration are also important in this regard (Shine et al., 2011). Harichand et al. (2002) observed that the treatment of MF at $10 \mathrm{mT}$ for $40 \mathrm{~h}$ boosted up the plant height, spike mass, and crop yield. Similarly, Vashisth and Nagarajan $(2008,2010)$ reported positive results in the

C 2013 Institute of Agrophysics, Polish Academy of Sciences 
growth of maize, chickpea, and sunflower seeds exposed to static magnetic field also at certain treatment levels. Furthermore, the exact MF doses to maximum response obtained can be optimized using response surface methodology (RMS).

The aim of this study was to show the effects of magnetic field pre-sowing pea seed treatment on growth, chlorophyll, and yield attributes.

\section{MATERIALS AND METHODS}

The authentic pea seeds were kindly supplied by Vegetable Section, Ayub Agricultural Research Institute, Faisalabad, Pakistan. For MF treatment, healthy and uniform size seeds were selected by hand picking, subjected to MF treatment and sown in a student research area, Department of Agronomy, University of Agriculture, Faisalabad. The selected seeds were soaked in water for $2 \mathrm{~h}$ and collected; next, extra moisture was removed by pressing in filter paper and the seeds were subjected to the MF treatment following a previously reported method (Iqbal et al., 2012). The MF treatments were applied under a factorial design (rotatable central composite design). The coded as well as natural values of selected variables are shown in Table 1 and the polynomial equation constructed for model can be seen in Eq. (1):

$$
\begin{aligned}
Y=\beta_{0} & +\beta_{1} X_{1}+\beta_{2} X_{2}+\beta_{12} X_{1} X_{2} \\
& +\beta_{1} X_{1}^{2}+\beta_{2} X_{2}^{2}+\epsilon
\end{aligned}
$$

where: $\beta_{0}, \beta_{1}$, and $\beta_{2}$ are coefficients, while $X_{1}$ (MF strength) and $X_{2}$ (exposure duration) are explanatory variables.

T a b l e 1. Experimental design showing coded and natural values of magnetic field and exposure duration

\begin{tabular}{rcccc}
\hline \multirow{2}{*}{ Run } & $\begin{array}{l}\text { MF* } \\
(\mathrm{mT})\end{array}$ & $\begin{array}{c}\text { Time } \\
(\mathrm{min})\end{array}$ & $\begin{array}{c}\text { MF } \\
(\mathrm{mT})\end{array}$ & $\begin{array}{c}\text { Time } \\
(\mathrm{min})\end{array}$ \\
\cline { 2 - 5 } & \multicolumn{2}{c}{ Coded values } & \multicolumn{2}{c}{ Natural values } \\
\hline 1 & -1 & -1 & 60 & 5 \\
2 & 0 & -1 & 120 & 5 \\
3 & 1 & -1 & 180 & 5 \\
4 & -1 & 0 & 60 & 10 \\
5 & 0 & 0 & 120 & 10 \\
6 & 1 & 0 & 180 & 10 \\
7 & -1 & 1 & 60 & 15 \\
8 & 0 & 1 & 120 & 15 \\
9 & 1 & 1 & 180 & 15 \\
10 & 1 & 0 & 120 & 10 \\
11 & 1 & 0 & 120 & 10 \\
12 & 1 & 0 & 120 & 10 \\
\hline
\end{tabular}

*MF - magnetic field, $\mathrm{mT}$ - milli tesla.
The growth parameter and chlorophyll contents were measured at the tasseling stage, while vine length and yield components were measured at maturity. The number of pods per plant, pod length, green pod yield plant ${ }^{-1}(\mathrm{~g})$ and green pod yield ha ${ }^{-1}\left(\mathrm{~kg} 10^{3}\right)$ were determined when the pods became fully mature. For dry and fresh masses, plants were uprooted and washed, and the roots and shoots were separated. After recording the fresh masses, the dry masses of shoots and roots were recorded after oven drying at $70^{\circ} \mathrm{C}$. The root, shoot, and vine length at maturity was measured with a carpenter tape. The chlorophyll contents were determined following the reported method (Iqbal et al., 2012) as:

$$
\begin{aligned}
& \text { Chl " } a "=12.70 \mathrm{~A}_{664.5}-2.79 \mathrm{~A}_{647} \\
& \text { Chl " } b "=20.70 \mathrm{~A}_{647}-4.62 \mathrm{~A}_{664.5}
\end{aligned}
$$

The data were manipulated using R, Statistical Software (Version 2.13) for ANOVA and predicted value, response surface diagrams, model selection and calculation of stationary points. The effect of the variables and their interaction were calculated at a $95 \%$ confidence interval for means.

\section{RESULTS}

The optimal response of various growth parameters, chlorophyll contents, and yield attributes were obtained using pre-sowing seed MF treatment in a pea cultivar (cv. Samrina Zard). Table 1 shows the coded experimental and natural variable levels, the order of runs, and the number of experiments seeded. Based on the differences between observed and predicted responses, the experimental error with a $95 \%$ confidence interval for the means was determined to evaluate the variable effects and their interaction (Table 2). By generating an experimental matrix with response of each parameter, the experimental variables were combined to construct a three-dimensional response surface plot in which synergism between the experimental variables can be seen, resulting in an optimal zone, where it is possible to identify the value of the variables given by the model in the form of optimal responses. The response surfaces of growth parameters, chlorophyll contents, and yield attributes are shown in Figs 1, 2.

The response surface indicates that root and shoot fresh masses were observed to be higher at $180 \mathrm{mT}$ for the 5 and 10 min exposure MF (Fig. 1a, b) and these values were 35.2 and $43.65 \%$, respectively, higher versus the control. The polynomial models obtained for root and shoot fresh masses are given in Eqs (2), (3). The shoot dry mass exhibited behaviour similar to fresh mass, while root dry mass was found to be slightly higher for the $120 \mathrm{mT}$ and $10 \mathrm{~min} \mathrm{MF} \mathrm{ex-}$ posure, however the difference was insignificant $(\mathrm{p}<0.05)$. The percent increase in shoot and root dry masses were 44.83 and $28.53 \%$ over the control. The polynomial models for shoot and root dry masses are shown in Eqs (4), (5), respectively, and the response surfaces constructed for shoot and root dry mass are shown in Fig. 1c, d. The percentage 
T a b l e 2. Analysis of variance for response surface models

\begin{tabular}{|c|c|c|c|c|c|c|c|c|}
\hline & $\mathrm{F}$ & $\mathrm{P}$ & $\mathrm{F}$ & $\mathrm{P}$ & F & $\mathrm{P}$ & F & $\mathrm{P}$ \\
\hline & \multicolumn{2}{|c|}{ RFM } & \multicolumn{2}{|c|}{ SFM } & \multicolumn{2}{|c|}{ SDM } & \multicolumn{2}{|c|}{ RDM } \\
\hline FO & 2.95 & 0.12 & 6.35 & $0.03 *$ & 12.9 & $0.006^{*}$ & 49.07 & $0.0001 *$ \\
\hline TWI & 27.86 & $0.0018^{*}$ & 36.9 & $0.0009^{*}$ & 868.93 & $<0.0001^{*}$ & 194.78 & $<0.0001^{*}$ \\
\hline PQ & 2.64 & 0.14 & 17.54 & $0.003^{*}$ & 7.38 & $0.02 *$ & 471.51 & $<0.0001^{*}$ \\
\hline \multirow[t]{2}{*}{ Lack of fit } & 255.9 & 0.0004 & 14.15 & 0.028 & 15.47 & 0.02 & 12.63 & 0.03 \\
\hline & \multicolumn{2}{|c|}{ SL } & \multicolumn{2}{|c|}{ RL } & \multicolumn{2}{|c|}{ Chl ' $a$ ' } & \multicolumn{2}{|c|}{ Chl ' $b$ ' } \\
\hline FO & 216.61 & $2 \mathrm{E}-06^{*}$ & 0.2 & 0.81 & 81.81 & $0.00004 *$ & 49.14 & $0.0001 *$ \\
\hline TWI & 1169.6 & $<0.0001 *$ & 6.58 & $0.04 *$ & 62.88 & $0.0002 *$ & 253.04 & $<0.0001 *$ \\
\hline PQ & 43.8 & $0.0002 *$ & 0.74 & 0.51 & 66.63 & $0.00007 *$ & 100.94 & $0.00002 *$ \\
\hline \multirow[t]{2}{*}{ Lack of fit } & 0.63 & 0.64 & 132.96 & 0.001 & 3.26 & 0.17 & 2.5 & 0.23 \\
\hline & \multicolumn{2}{|c|}{ VLM } & \multicolumn{2}{|c|}{ GPY/P } & \multicolumn{2}{|c|}{ Pod L } & \multicolumn{2}{|c|}{ GPY ha ${ }^{-1}$} \\
\hline FO & 923.95 & $<0.0001^{*}$ & 32.56 & $0.0006^{*}$ & 11.68 & $0.008^{*}$ & 26.67 & $0.001 *$ \\
\hline TWI & 4566.4 & $<0.0001 *$ & 151.65 & $0.00001 *$ & 59.24 & $0.0002 *$ & 1166.4 & $<0.0001 *$ \\
\hline PQ & 126.51 & $0.00001 *$ & 200.24 & $<0.0001 *$ & 30.34 & $0.0007^{*}$ & 176.18 & $<0.0001^{*}$ \\
\hline Lack of fit & 6.81 & 0.07 & 2.72 & 0.216 & 132.96 & 0.001 & 2.54 & 0.231 \\
\hline
\end{tabular}

*Significant at a 95\% confidence interval for the mean: FO - first order, TWI - two-way interaction, PQ - pure quadratic, RFM - root fresh mass, SFM - shoot fresh mass, SDM - shoot dry mass, RDM - root dry mass, SL - shoot length, RL - root length, Chl - chlorophyll, VLM - vine length at maturity, GPY/P - green pod yield/plant, Pod L - pod length, GPY ha ${ }^{-1}-$ green pod yield ha ${ }^{-1}$.
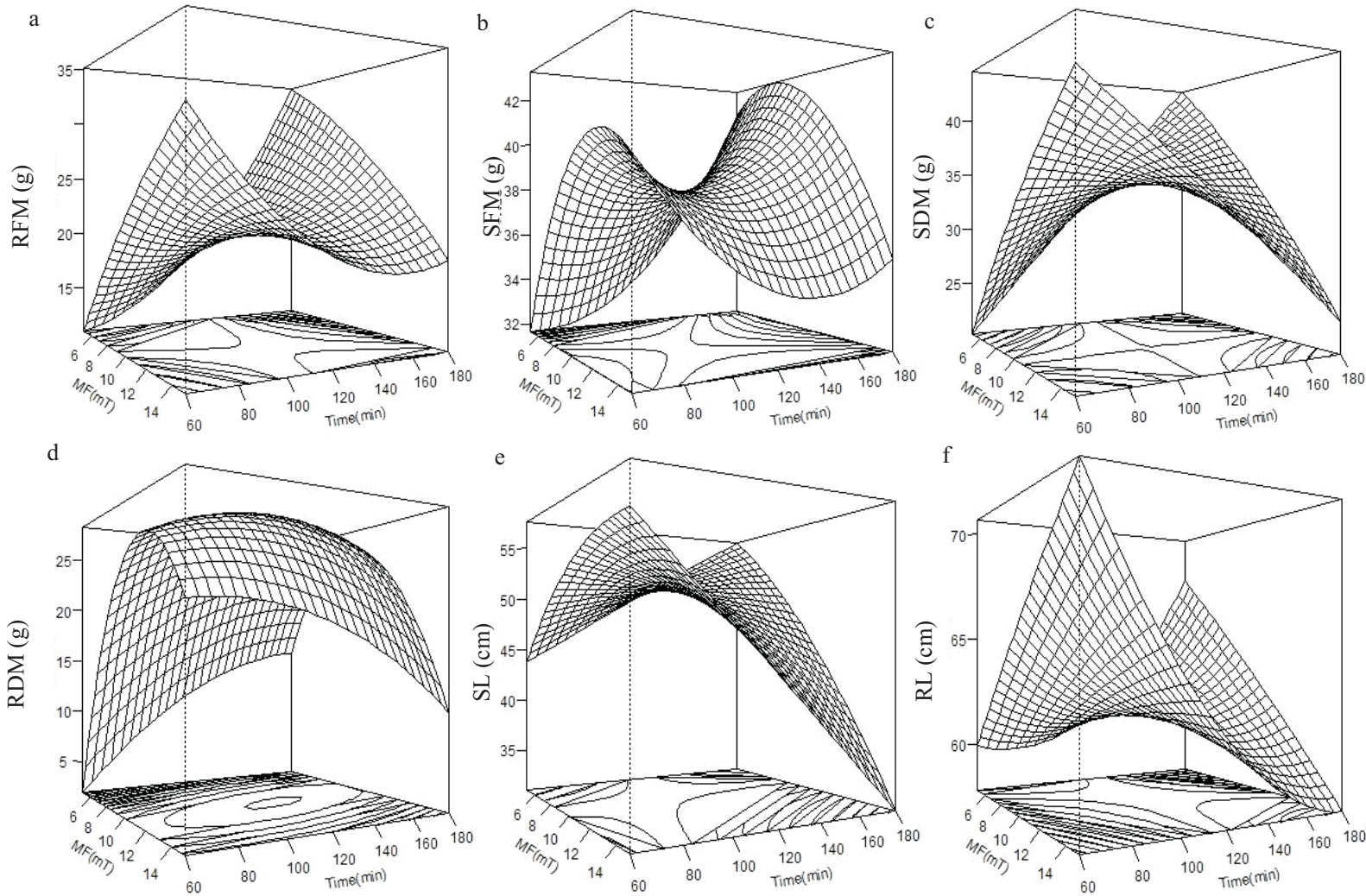

Fig. 1. Response surfaces for the experimental design of the growth parameters in pea obtained from plants treated with magnetic field: $\mathrm{a}$ - root fresh mass, $\mathrm{b}$ - shoot fresh mass, $\mathrm{c}$ - shoot dry mass, $\mathrm{d}$ - root fresh mass, $\mathrm{e}$ - shoot length, and $\mathrm{f}$ - root length. 
increase in shoot and root lengths were observed to reach up to 57.33 and $71.42 \%$ at the MF doses of $180 \mathrm{mT}$ for $5 \mathrm{~min}$ and $60 \mathrm{mT}$ for $15 \mathrm{~min}$ of exposure, respectively. The models obtained for shoot and root lengths are shown in Eqs (6), (7) and the response surfaces in Fig. 1e, f, respectively:

$\mathrm{Y}(\%)$ Root fresh mass $=-9.38( \pm 11.22)+0.03( \pm 0.14)$

$$
\begin{gathered}
X_{1}+4.79( \pm 1.76) X_{2}-0.02( \pm 0.005) \\
X_{1} X_{2}-0.001( \pm 0.0005) X_{1}^{2}+\in
\end{gathered}
$$

$\mathrm{Y}(\%)$ Shoot fresh mass $=16.08( \pm 3.90)-0.04( \pm 0.05)$

$$
\begin{gathered}
X_{1}+4.51( \pm 0.61) X_{2}-0.01( \pm 0.001) \\
X_{1} X_{2}-0.0007( \pm 0.0001) X_{1}^{2}-0.15( \pm 0.02) X_{2}^{2}+\in
\end{gathered}
$$

$\mathrm{Y}(\%)$ Shoot dry mass $=-18.0( \pm 2.43)+0.3( \pm 0.03)$

$$
\begin{gathered}
X_{1}+5.35( \pm 3.84) X_{2}-0.03( \pm 0.001) \\
X_{1} X^{2}-0.05( \pm 0.001) X_{2}{ }^{2}+\in
\end{gathered}
$$

$\mathrm{Y}(\%)$ Root dry mass $=-67.67( \pm 2.75)+0.4( \pm 0.03)$
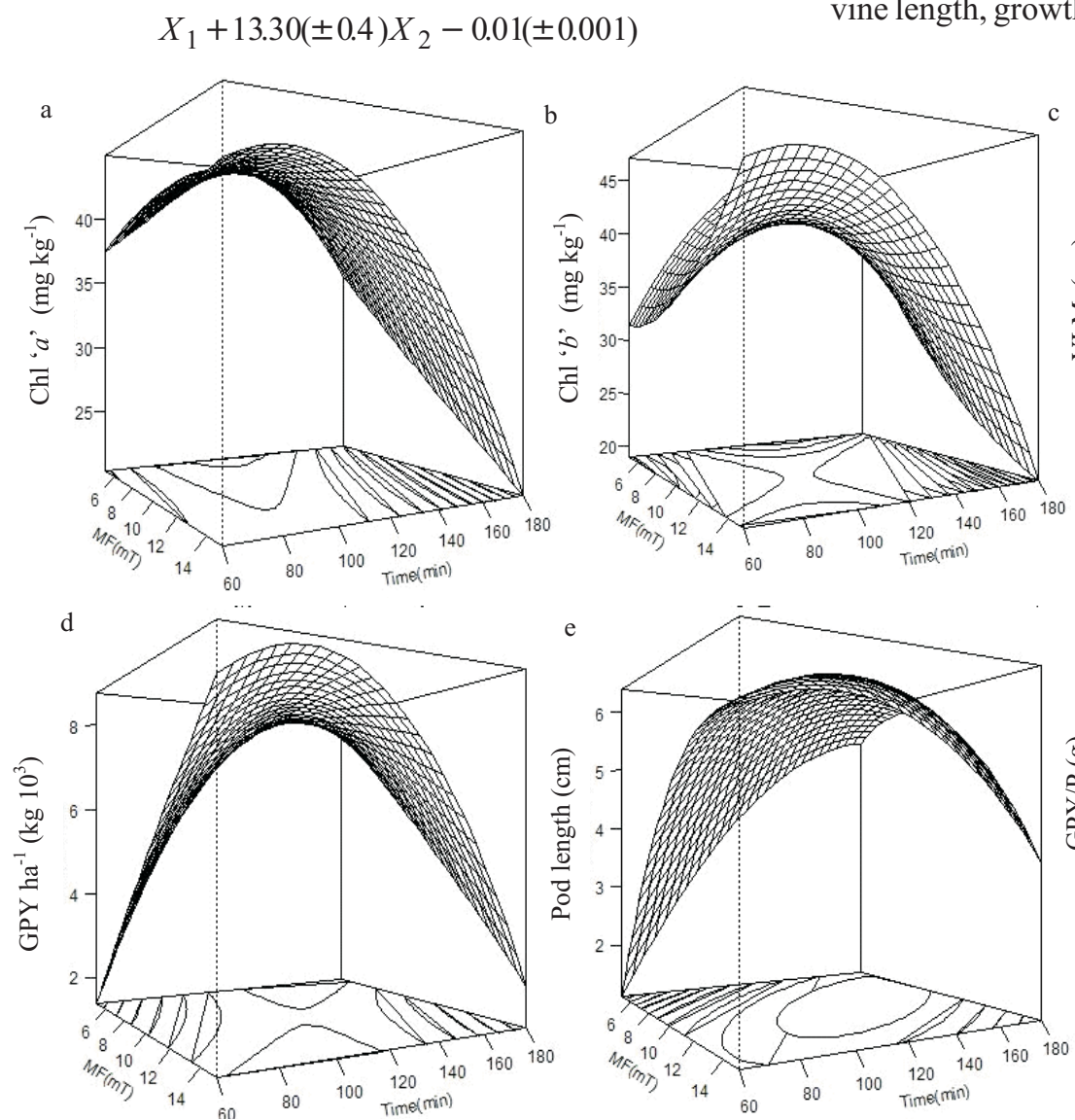

$$
\begin{gathered}
X_{1} X_{2}-0.008( \pm 0.0001) X_{1}^{2}-0.5( \pm 0.01) X_{2}{ }^{2}+\in \\
\mathrm{Y}(\%) \text { Shoot length }=13.04( \pm 1.8)+0.2( \pm 0.02) \\
X_{1}+5.20( \pm 0.2) X_{2}-0.03( \pm 0.0009) X_{1} X_{2} \\
-0.1( \pm 0.001) X_{2}{ }^{2}+\in
\end{gathered}
$$

$$
\begin{aligned}
& \mathrm{Y}(\%) \text { Root length }=53.13( \pm 14.06)-0.04( \pm 0.1) \\
& X_{1}+2.38( \pm 2.21) X_{2}-0.01( \pm 0.006) X_{1} X_{2}+\in
\end{aligned}
$$

The chlorophyll contents, vine length at maturity, and yield components were also enhanced significantly $(\mathrm{p}<0.05)$ in the MF-treated group of plants $v s$. the control. The content of chlorophyll ' $a$ ' and ' $b$ ' was enhanced at $120 \mathrm{mT}$ for 5 min exposure (Fig. 2a, b). The polynomial models obtained for chlorophyll ' $a$ ' and ' $b$ ' are shown in Eqs (8), (9). The response surface indicates that vine length at maturity and pod length reached the maximum at $180 \mathrm{mT}$ for 5 and $10 \mathrm{~min} \mathrm{MF}$ exposure, respectively (Fig. 1c-e) and these values were 35.2 and $43.65 \%$ higher than the control, respectively; the polynomial models constructed are given in Eqs (10), (11). The yield components were found to be correlated with the vine length, growth parameter and chlorophyll content. The

Fig. 2. Response surfaces for the experimental design of the pea chlorophyll contents and yield components obtained from plants treated with magnetic field: $\mathrm{a}-\mathrm{Chl}$ ' $a$ ' $\left(\mathrm{mg} \mathrm{kg}^{-1}\right), \mathrm{b}-\mathrm{Chl}^{\prime} b^{\prime}$ ( $\left.\mathrm{mg} \mathrm{kg}^{-1}\right), \mathrm{c}$ - final vine length $(\mathrm{cm}), \mathrm{d}-$ green pod yield ha ${ }^{-1}\left(\mathrm{~kg}^{1} 0^{3}\right), \mathrm{e}-$ pod length $(\mathrm{cm})$, and $\mathrm{f}-$ green pod yield plant $^{-1}(\mathrm{~g})$. 
response surfaces of green pod yield plant $^{-1}$ and green pod yield $\mathrm{ha}^{-1}$ showed that maximum responses were observed at $180 \mathrm{mT}$ for $5 \mathrm{~min}$ exposure and $60 \mathrm{mT}$ for $15 \mathrm{~min} \mathrm{ex}$ posure; however, the response was marginally higher in the case of $60 \mathrm{mT}$ for $15 \mathrm{~min}$ exposure (Fig. 1d-f). The polynomial models constructed for green pod yield plant ${ }^{-1}$ and green pod yield ha ${ }^{-1}$ are shown in Eqs (12), (13). Generally, it was found that the doses of low MF strength for the longer exposure duration and the high strength for the shorter exposure time were found more effective as compared to other treatments:

$$
\begin{gathered}
\mathrm{Y}(\%) \mathrm{Chl} \text { ' } a \text { '= } 8.11( \pm 4.08)+0.6( \pm 0.05) \\
X_{1}+1.12( \pm 1.75) X_{2}-0.01( \pm 0.002) \\
X_{1} X_{2}-0.002( \pm 0.0002) X_{1}^{2}+\in \\
\mathrm{Y}(\%) \mathrm{Chl} ' b \text { ' }=-6.79( \pm 3.6)+0.8( \pm 0.04) \\
X_{1}+0.26( \pm 0.57) X_{2}-0.02( \pm 0.001) \\
X_{1} X_{2}-0.002( \pm 0.0001) X_{1}^{2}+0.12( \pm 0.02) X_{2}{ }^{2}+\in
\end{gathered}
$$

$\mathrm{Y}(\%)$ Vine length at maturity $=-28.77( \pm 1.83)$$$
+0.4( \pm 0.02) X_{1}+5.24( \pm 0.2) X_{2}-0.06( \pm 0.0008)
$$$$
X_{1} X^{2}+0.001( \pm 0.00001) X_{1}^{2}+\in
$$

$\mathrm{Y}(\%)$ Pod length $=-11.9( \pm 1.4)+0.13( \pm 0.018)$

$X_{1}+1.97( \pm 0.2) X_{2}-0.005( \pm 0.0007)$

$X_{1} X_{2}-0.0002( \pm 0.00002) X_{1}^{2}-0.05( \pm 0.001) X_{2}{ }^{2}+\in$

$$
\begin{gathered}
\mathrm{Y}(\%) \text { Green pod yield plant }{ }^{-1}=-19.4( \pm 1.15) \\
+0.3( \pm 0.01) X_{1}+1.83( \pm 0.1) X_{2}-0.007( \pm 0.0005) \\
X_{1} X_{2}-0.0009( \pm 0.00005) X_{1}^{2}-0.05( \pm 0.008) X_{2}{ }^{2}+\in
\end{gathered}
$$

$$
\mathrm{Y}(\%) \text { Green pod yield ha } \mathrm{ha}^{-1}=-10.25( \pm 0.9)+0.3( \pm 0.01)
$$

$$
\begin{gathered}
X_{1}+1.93( \pm 0.15) X_{2}-0.008( \pm 0.0004) \\
X_{1} X_{2}-0.05( \pm 0.007) X_{1}^{2}-0.05( \pm 0.007) X_{2}{ }^{2}+\epsilon
\end{gathered}
$$

While solving statistically the experimental matrix, the model equation was developed for all the measured parameters in which linear as well as quadratic relations were found significant $(p<0.05)$. The importance of the parameters in the mathematical solution was obtained from the experimental design, against the mass of each variable (MF strength and exposure time). Thus, an empirical relationship between the response and the variables was expressed by the polynomial equations in the form of response ( $\mathrm{Y} \%)$ and variables
$\left(\mathrm{X}_{1}\right.$ and $\mathrm{X}_{2}$ ). The $\mathrm{Y}, \mathrm{X}_{1}$, and $\mathrm{X}_{2}$ represent the response, $\mathrm{MF}$ strength, and MF exposure time, respectively, (Eqs (2)-(13)) in each parameter. Stationary points (maximum point of interest in responses) of MF strength and MF exposure time for each parameter were also calculated; they were found different for each parameter, but in a specific range. For the growth parameters such as root fresh mass, shoot fresh mass, shoot dry mass, root dry mass, shoot length and root length, the best levels of MF doses (strength and exposure time) were found to be $116.04 \mathrm{mT}(11.51 \mathrm{~min}), 106.37 \mathrm{mT}$ (10.59), $116.67 \mathrm{mT}$ (10.71 min), $128.04 \mathrm{mT}$ (10.43 min), $103.33 \mathrm{mT}$ (8.78 $\mathrm{min})$, and $121.56 \mathrm{mT}$ (9.12 $\mathrm{min})$, respectively. Similarly, the maximum response of chlorophyll ' $a$ ' and ' $b$ ', vine length at maturity, pod length, green pod yield plant ${ }^{-1}$ and green pod yield ha ${ }^{-1}$ was found at MF doses of $85.47 \mathrm{mT}$ (14 min), $105.74 \mathrm{mT}$ (10.75 min), 97.76 $\mathrm{mT}$ (10.80 $\mathrm{min}), 142.47 \mathrm{mT}$ (9.75 min), $116.18 \mathrm{mT}$ (10.70 $\mathrm{min}), 136.61 \mathrm{mT}(8.16 \mathrm{~min})$, and $140 \mathrm{mT}$ (7.66 $\mathrm{min})$, respectively.

Statistical analyses showed that the proposed models were significant, and it can be seen form the polynomial equation that the responses were influenced by the combined effect of variables (MF strength and duration of exposure). Figure 3 depicts the influence of each variable with correlation coefficient values ( $\%)$ for the statistics at a $95 \%$ confidence interval of the means. All the measured parameters were influenced directly by the MF strength and exposure duration. However, the influence of the MW exposure time was superior as compared to the MF strength. Other than the first order terms, the second order terms were also found significant for chlorophyll ' $a$ ' and ' $b$ ', shoot fresh mass, pod length, green pod yield/plant, root dry mass, shoot dry mass, vine length at maturity, and green pod yield $\mathrm{ha}^{-1}$. All the models constructed for the growth parameters, chlorophyll contents and yield components were statistically evaluated as valid showing higher $\mathrm{R}^{2}$ and $\mathrm{R}^{2}$ adjusted values. The $\mathrm{R}^{2}\left(\mathrm{R}^{2}\right.$ adj) were found to be $0.866(0.755)$, 0.933(0.878), 0.993(0.988), 0.995(0.991), 0.996(0.993), 0.983(0.969), 0.989(0.98), 0.999(0.998), 0.996(0.993), and 0.993(0.98), respectively, for: root fresh, shoot fresh, shoot dry, root dry mass; shoot length, chlorophyll ' $a$ ' and ' $b$ ', vine length at maturity, green pod yield plant ${ }^{-1}$, pod length, and green pod yield $\mathrm{ha}^{-1}$. The $\mathrm{R}^{2}$ and $\mathrm{R}^{2}$ adjusted value indicates that the regression model provides a good description of the relationships between the independent variables and the responses because $\mathrm{R}^{2}$ represents the fraction of variation in the response explained by the model and evaluated by the statistical validity of the model with $p=0.001$. The plot (observed versus predicted) was also constructed for the measured parameters, which showed a straight line and confirmed the normality in the data (Figs 4, 5). Furthermore, the fitted models provided a good approximation to the experimental condition and were employed to deduce the values of the process variables for maximum response. 

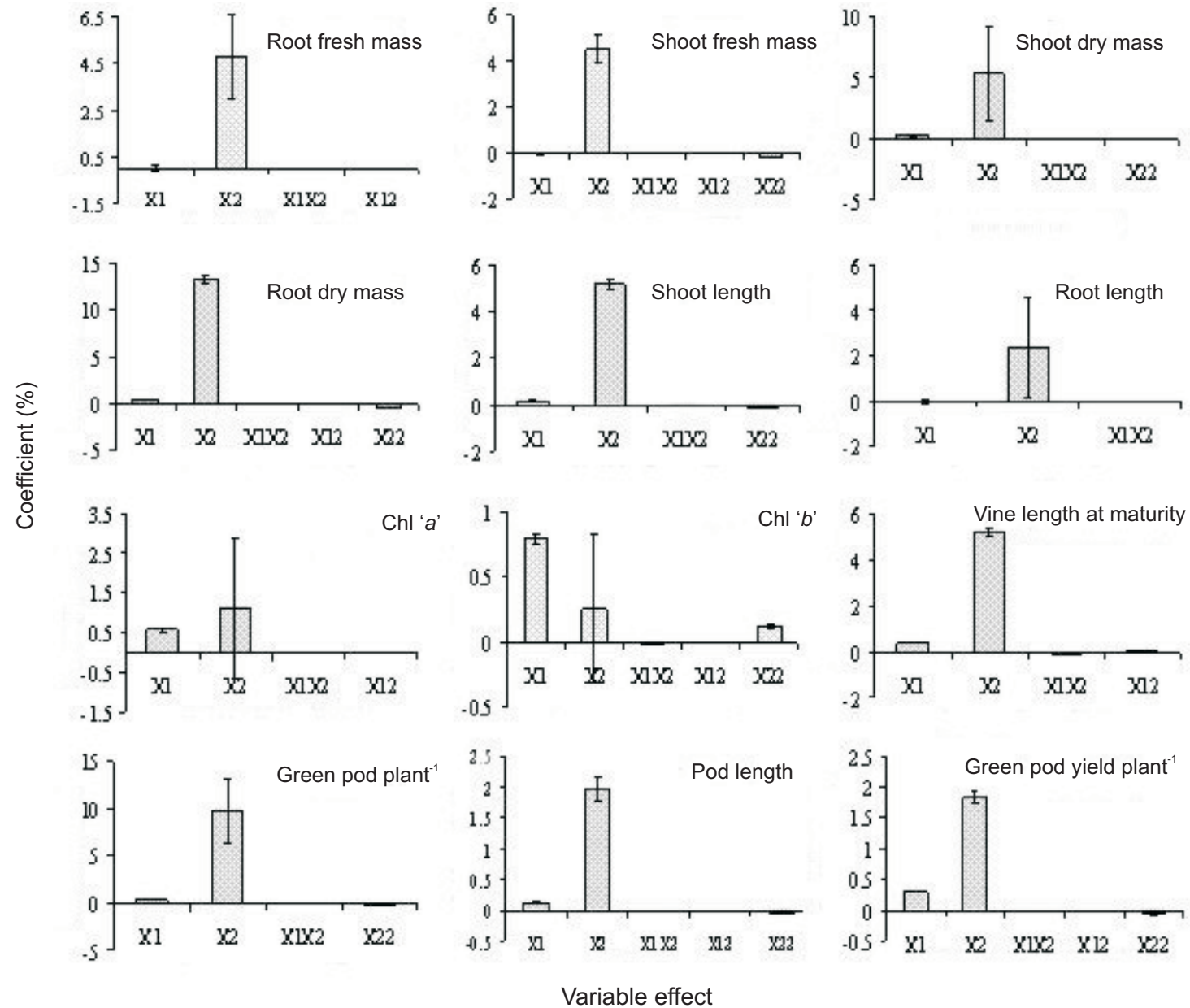

Fig. 3. Analysis of the influence of variables on the growth parameters in pea plant raised from magnetic field treated seeds at a $95 \%$ confidence interval, $\mathrm{X}_{1}$ and $\mathrm{X}_{2}$ represent the magnetic field strength and exposure duration, respectively.

The ANOVA (Table 2) showed that the models generated were significant for all the measured parameters. In other words, the first order two-way interaction and the second order terms were significant. Therefore, the models proposed were appropriate, since we have included the first order two-way interaction as well as the second order terms (significant only) for optimization of the effect of the MW strength and exposure duration on growth parameters, chlorophyll contents, and yield attributes in the pea cultivar.

\section{DISCUSSION}

The growth parameters, chlorophyll contents, and yield components were positively affected by the MF pre-sowing seed treatment. However, the MF treatment exhibited a positive trend at a certain in comparison to other treatments eg low MF treatment for a longer time and high MF level for shorter time duration were found more effective. The MF level of $180 \mathrm{mT}$ for $5 \mathrm{~min}$ exposure, $120 \mathrm{mT}$ for $10 \mathrm{~min}$, and $60 \mathrm{mT}$ for $15 \mathrm{~min}$ resulted in higher acceleration in the growth, chlorophyll contents, and yield attributes, and application of the response surface methodology further explored the specific level eg $116.04 \mathrm{mT}$ (11.51 min), $85.47 \mathrm{mT}$ (14 $\mathrm{min})$, and $136.61 \mathrm{mT}(8.16 \mathrm{~min})$ and found specific points (stationary points) for root fresh mass, chlorophyll contents and green pod yield plant ${ }^{-1}$, respectively, etc. Similar studies concerning the MF pre-sowing seed treatment were also well documented previously. However, studies of the application of the response surface methodology for optimization of operating parameters are rare. According to Zia et al. (2012), the MF effect on germination, growth, and biochemical, physiological, and enzymatic attributes is dose dependent and Harichand et al. (2002) observed that the MF treatment of $10 \mathrm{mT}$ for $40 \mathrm{~h}$ boosted up the plant height, spike mass, and yield. Florez et al. (2007) reported enhancement in rice germination when exposed to $125 \mathrm{mT} / 250 \mathrm{mT}$ and Iqbal et al. (2012) found $120 \mathrm{mT}$ for $15 \mathrm{~min}$ and $180 \mathrm{mT}$ for $10 \mathrm{~min}$ to be most efficient in increasing growth characteristics. Similarly, Atak et al., 2007; Fischer et al., 2004; Yano et al., 2004; and 

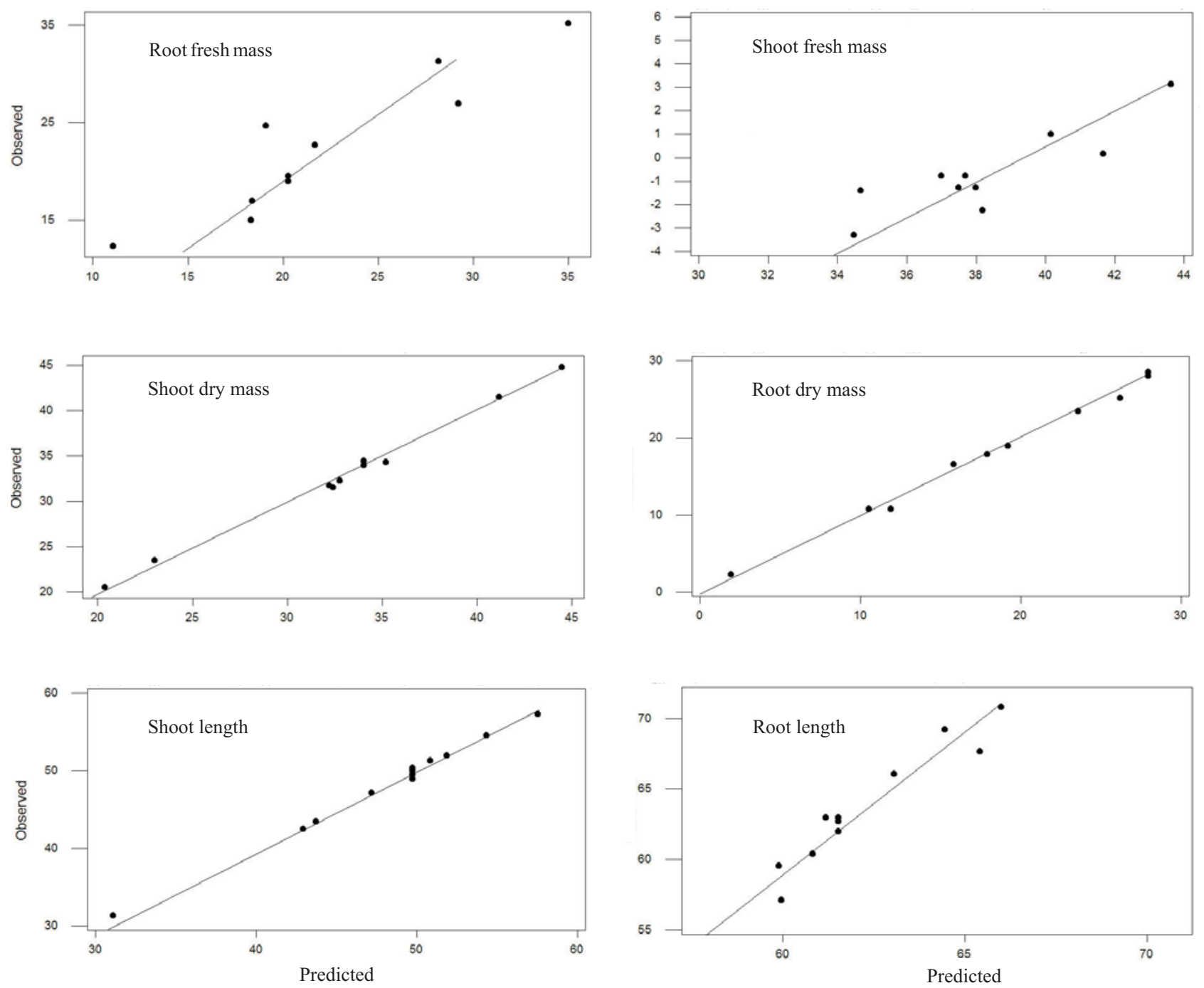

Fig. 4. Plot of observed versus predicted values of growth parameters in pea plants raised from magnetically treated seeds.

Yinan et al., 2005; revealed that 50 and $150 \mathrm{mT}$ for $2 \mathrm{~h}$ and 100 $\mathrm{mT}$ for $1 \mathrm{~h}$ were able to stimulate seed germination, growth, and enzymatic attributes in maize, chickpea, and sunflower.

The promising effect of MF on growth and yield components might be attributed to the increase in the photosynthetic rate and other endogenous promoters such as protein biosynthesis and accumulation of biomolecules (Shine et al., 2011). In this regard, Belyavskaya (2001 and 2004), reported that MF significantly accelerated cell metabolism and meristematic cell mitosis in pea, lentil, and flax. Moreover, formation of new protein bands in plants treated with MF may be responsible for the stimulation of growth and ultimately yield. In this respect, Çelik et al. (2008) found that the increase in the percentage of plant regeneration is due to the effect of MF on cell division and protein synthesis in paulownia nodes.
The growth, physiological, and biochemical attributes in plants are regulated by various internal moieties as well as external factors. Furthermore, the receptors respond with the environment according to their metabolic requirement. The MF treatment in general stimulates positive changes at certain levels which need proper optimization of the operating parameters viz. MF strength and time of seed exposure. The response to the MF treatment has been studied well by researchers all over the world; however, the optimization of operating parameters using a design is rare in this field. In the present study, we have applied the response surface methodology for optimization of MF doses on various growth parameters, chlorophyll contents, and yield attributes in a pea cultivar and based on the results it is concluded that the response surface methodology optimized the operating parameter precisely. 

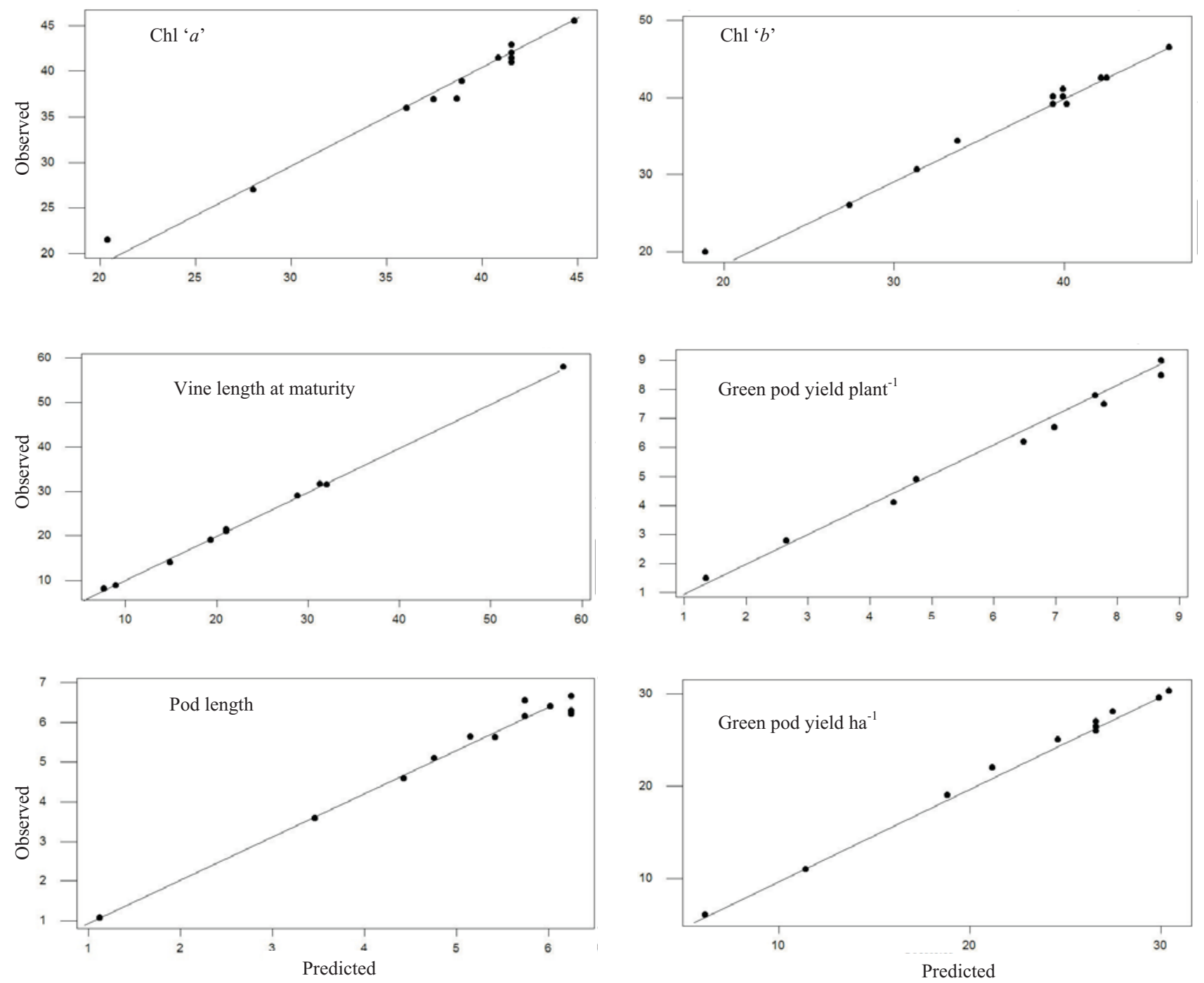

Fig. 5. Plot of observed versus predicted values of chlorophyll and yield attributes in pea plants raised from magnetically treated seeds.

The action of the MF effect on growth is not well known, and it was reported that the MF seed pre-sowing treatment affected the membrane physiology and, consequently, the biochemical, physiological, and metabolic moieties can be altered (Zia et al., 2012). The permeable membranes allow more ion transportation in the ion channels, which as a result affects the metabolic pathways. The MF treatment affects the biological objects by non-conventional spins, free radicals, liquids crystals, or mobile electron charges as well. Chemically, these free radicals are very active species, which take part in reactions very fast and cause changes in the biochemical and physiological moities at the cellular level during germination, growth, and development at lateral stages (Iqbal et al., 2012). Furthermore, an increase in the water uptake rate due to MF treatment has also been reported elsewhere (Podleśny et al., 2004; Zia et al., 2012). One theory of the MF interaction with biological systems is 'radical-pair mechanism' consisting of modulation of single-triplet inter-conversion rates of a radical pair. The MF increased the average radical concentration, prolonging their life time and enhancing the probability of radical reaction with cellular components (Atak et al., 2007).

\section{CONCLUSIONS}

1. The magnetic field treatments were found effective to enhance the growth characteristics, chlorophyll contents, and yield components.

2. The magnetic field level were effective at certain levels.

3. Low magnetic field strength for the longer time of exposure and high magnetic for shorter duration were found the most effective in enhancing the growth and yield in the pea cultivar.

4. The use of the experimental design demonstrates that this is an efficient tool for determining the efficiency of 
treatments with a statistically reliable analysis and optimization of the variables for individual parameters.

5. This study is also extendable to other crops for estimation of exact magnetic field doses to obtain the maximum response of interest.

\section{REFERENCES}

Amjad M. and Anjum M.A., 2002. Performance of nine pea cultivars under Faisalabad conditions. Pakistan J. Agric. Sci., 39, 6-19.

Atak C., Çelik Ö.A., Olgun S., and Alikamanoglu A.R., 2007. Effect of magnetic field on peroxidase activities of soybean tissue culture. Biotech. Biotech. EQ., 21, 166-171.

Belyavskaya N.A., 2001. Ultrastructure and calcium balance in meristem cells of pea roots exposed to extremely low magnetic field. Adv. Space Res., 28, 645-650.

Belyavskaya N.A., 2004. Biological effects due to weak magnetic field on plants. Adv. Space Res., 34, 1566-1574.

Çelik Ö., Atak Ç.A., and Rzakulieva A., 2008. Stimulation of rapid regeneration by a magnetic field in paulownia node cultures. J. Central Eur. Agric., 9, 297-303.

De Souza A., Garcí D., Sueiro L., Gilart F., Porras E., and Licea L., 2006. Pre-sowing magnetic treatments of tomato seeds increase the growth and yield of plants. Bioelectromagnetics, 27, 247-257.

Fischer G., Tausz M., Köck M., and Grill D., 2004. Effect of weak $162 / 3 \mathrm{HZ}$ magnetic fields on growth parameters of young sunflower and wheat seedlings. Bioelectromagnetics, $25,638-641$.

Florez M., Carbonell M.V., and Martinez E., 2007. Exposure of maize seeds to stationary magnetic fields: effects on germination and early growth. Environ. Exp. Bot., 59, 68-75.

Harichand K.S., Narula V., Raj D., and Singh G., 2002. Effect of magnetic fields on germination, vigour and seed yield of wheat. Seed Res., 30, 289-93.

Iqbal M., Zia ul Haq, Jamil Y., and Ahmad M.R., 2012. Effect of pre-sowing magnetic treatment on growth and chlorophyll contents of pea. Int. Agrophys., 26, 1-7.

Marks N. and Szecówka P.S., 2010. Impact of variable magnetic field stimulation on growth of aboveground parts of potato plants. Int. Agrophys., 24, 165-170.
Martinez E., Carbonell M.V., Flórez M., Amaya J.M., and Maqueda R., 2009. Germination of tomato seeds (Lycopersicon esculentum L.) under magnetic field. Int. Agrophys., 23, 45-49.

Nisar M., Ghafoor A., Ahmad H., Khan M.R., Qureshi A.S., Ali H., and Islam M., 2008. Evaluation of genetic diversity of pea germplasm through phenotypic trait analysis. Pakistan J. Bot., 40, 2081-2086.

Pietruszewski S., 2007. Electromagnetic fields and electromagnetic radiation as non-invasive external simulations for seeds. Int. Agrophysics, 21, 95-100.

Podleśny J., Pietruszewski S., and Podleśna A., 2004. Efficiency of the magnetic treatment of broad bean seeds cultivated under experimental plot conditions. Int. Agrophysics, 18, 65-71.

Shine M.B., Guruprasad K.N., and Anan A., 2011. Enhancement of germination, growth, and photosynthesis in soybean by pre-treatment of seeds with magnetic field. Bioelectromagnetics. 32, 474-484.

Vashisth A. and Nagarajan S., 2008. Exposure of seeds to static magnetic field enhances germination and early growth characteristics inchick pea (Cicer arietinum L). Bioelectromagnetics, 29, 571-578.

Vashisth A. and Nagarajan S., 2010. Effect on germination and early growth characteristic in sunflower (Helianthus annuus) seeds exposed to static magnetic field. J. Plant Physiol., 167, 149-156.

Yano A., Ohashi Y., Hirasaki T., and Fujiwara K., 2004. Effects of a $60 \mathrm{~Hz}$ magnetic field on photosynthetic $\mathrm{CO}_{2}$ uptake and early growth of radish seedlings. Bioelectromagnetics, 25 , 572-581.

Yinan Y., Yuan L., Yongqing Y., and Chunyang L., 2005. Effect of seed pretreatment by magnetic field on the sensitivity of cucumber (Cucumis sativus) seedlings to ultraviolet-B radiation. Environ. Experi. Bot., 54, 286-294.

Zepeda R.B., Hernandez C.A., Suazo F.L., Dominguez A.P., Cruz A.O., and Martínez E.O., 2011. Physical characteristics of maize grain and tortilla exposed to electromagnetic field. Int. Agrophys., 25, 389-393.

Zia ul Haq., Jamil Y., Irum S., Randhawa M.A., Iqbal M., and Amin N., 2012. Enhancement in the germination, seedling growth and yield of radish (Raphanus sativus) using seed pre-sowing magnetic field treatment. Polish J. Environ. Stud., 21, 369-374. 